\title{
Commentary: Fenestration and stenting technique and malperfusion syndrome-To give to Caesar what is Caesar's
}

\author{
Francesco Formica, MD, ${ }^{a, b, c}$ and Stefano D'Alessandro, MD, FECTS
}

\footnotetext{
From the ${ }^{\mathrm{a}}$ Mechanical Circulatory Support Program, Cardiac Surgery Unit and ${ }^{\mathrm{c}}$ Cardiac Surgery Unit, Cardio-thoracic-vascular Department, San Gerardo Hospital, Monza, Italy; and ${ }^{\mathrm{b}}$ Department of Medicine and Surgery, University of Milano-Bicocca, Monza, Italy.

Disclosures: Authors have nothing to disclose with regard to commercial support.

Received for publication Sept 11, 2019; revisions received Sept 11, 2019; accepted for publication Sept 11, 2019; available ahead of print Sept 24, 2019.

Address for reprints: Francesco Formica, MD, Clinica Cardiochirurgica Ospedale San Gerardo, ASST Monza, Via G.B. Pergolesi 33, 20052, Monza (MB), Italy (E-mail: francesco_formica@fastwebnet.it).

J Thorac Cardiovasc Surg 2020;160:1164-5

0022-5223/\$36.00

Copyright (c) 2019 by The American Association for Thoracic Surgery

https://doi.org/10.1016/j.jtcvs.2019.09.055
}

The interest for the endovascular treatment of acute type $B$ aortic dissection (ATBAD) has been increasing during the last decades as a result of improved imaging technologies, prompt diagnosis, improved preoperative and postoperative management, and improved experience of the aortic team. This evolution has determined reduced early morbidity and mortality and improved long-term survival. ${ }^{1}$ Advanced endovascular techniques, such as thoracic endovascular aortic repair (TEVAR) with stent-graft deployment and dissection flap fenestration with branch stenting repair, are considered the treatment of choice in ATBAD with malperfusion syndrome., ${ }^{2,3}$

In this issue of the Journal, Norton and coauthors ${ }^{4}$ present their data regarding the use of the endovascular fenestration and stenting technique in a consecutive series of 182 patients who had ATBAD with malperfusion in a period spanning between 1996 and 2018 at the University of Michigan. Of 182 patients, 99 underwent aortic fenestration and stenting, and 108 underwent branch vessel fenestration and stenting. Forty-eight patients did not receive any interventional therapy. Norton and coauthors ${ }^{4}$ reported a low early mortality, which was $7.7 \%$ in all cohorts and even $0 \%$ during the last 8 years. Furthermore, a low incidence of new-onset paraplegia of $0 \%$ and a stroke incidence of $5.5 \%(n=10)$ were reported. Survivals at 5 and 10 years were $72 \%$ and $49 \%$, respectively. Of note, TEVAR was used only in 9 patients $(4.9 \%)$ because of the imminent risk of aortic rupture. These results demonstrate the great experience and the high rate of success of the fenestration and stenting technique of the team from the University of Michigan, who have developed and implemented this attractive endovascular technique. ${ }^{5}$ An interesting point of focus is the type of technique to use depending on the mechanism of aortic branch vessel obstruction. Dynamic obstruction should be managed only with a TEVAR procedure. With this approach, the deployment of a stent graft

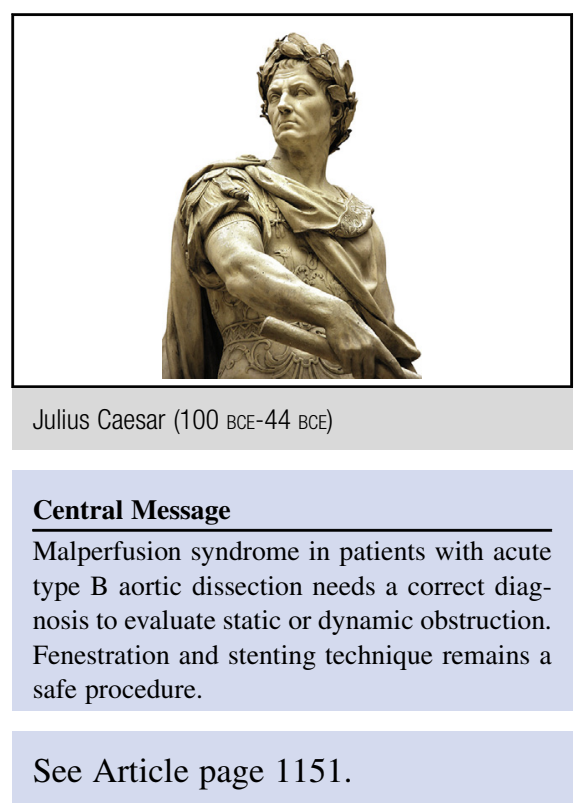

usually covers the proximal entry tear and restores an adequate branch inflow by promoting the thrombosis of the false lumen and reducing the compression. Static obstruction represents a more complex scenario, because TEVAR alone maybe not useful to resolve the obstruction, and a fenestration and stenting procedure therefore becomes the first option. Norton and coauthors ${ }^{4}$ do not report a subclassification of patients according to the mechanism of obstruction, and they used the endovascular fenestration and stenting for all patients with malperfusion. There was no TEVAR control group, and a distinction among patients with static or dynamic obstruction or both is missing. It is therefore difficult to understand whether TEVAR alone can reliably resolve the dynamic obstruction in this cohort of patients. TEVAR is an easier procedure than endovascular fenestration and stenting. The latter requires extensive endovascular experience and skill ${ }^{6}$ and should be performed in high-volume center. In case of complex malperfusion syndrome caused by ATBAD, the first point to be evaluated is therefore whether the team may go ahead with the procedure or should transfer the patient to a more experienced referral center to offer a higher probability of success. This option is sometime neglected, even though it may be the best option: "Reddite quae sunt Caesaris Caesari" [to give to Caesar what is Caesar's]. 


\section{References}

1. Evangelista A, Isselbacher EM, Bossone E, Gleason TG, Eusanio MD, Sechtem U, et al; IRAD Investigators. Insights from the international registry of acute aortic dissection: a 20-year experience of collaborative clinical research. Circulation. 2018;137:1846-60.

2. Khayat M, Cooper KJ, Khaja MS, Gandhi R, Bryce YC, Williams DM. Endovascular management of acute aortic dissection. Cardiovasc Diagn Ther. 2018; 8(Suppl 1):S97-107.

3. Vendrell A, Frandon J, Rodiere M, Chavanon O, Baguet JP, Bricault I, et al. Aortic dissection with acute malperfusion syndrome: endovascular fenestration via the funnel technique. J Thorac Cardiovasc Surg. 2015;150:108-15.

4. Norton EL, Williams DM, Kim KM, Khaja SM, Wu X, Patel HJ, et al. Management of acute type B aortic dissection with malperfusion via endovascular fenestration/stenting. J Thorac Cardiovasc Surg. 2020;160: 1151-61.e1.

5. Williams DM, Lee DY, Hamilton BH, Marx MV, Narasimham DL, Kazanjian SN, et al. The dissected aorta: percutaneous treatment of ischemic complications-principles and results. J Vasc Interv Radiol. 1997;8:605-25.

6. DiMusto PD, Williams DM, Patel HJ, Trimarchi S, Eliason JL, Upchurch GR Jr. Endovascular management of type B aortic dissections. J Vasc Surg. 2010;52(4 Suppl):26S-36S. 